The Clinical Utility of Social Information Processing Theory in Assessing and Treating Offenders with Autism Spectrum Disorder

\begin{tabular}{|r|l|}
\hline Journal: & Advances in Autism \\
\hline Manuscript ID & AIA-07-2016-0019.R1 \\
\hline Manuscript Type: & Review Paper \\
\hline Keywords: & $\begin{array}{l}\text { Offending behaviour, Forensic, Criminal Justice System, Autism Spectrum } \\
\text { condition, Autism Spectrum Disorder, Autism }\end{array}$ \\
\hline \multicolumn{2}{|c}{} \\
\end{tabular}

SCHOLARONE $^{\text {IM }}$

Manuscripts 


\title{
The Clinical Utility of Social Information Processing Theory in Assessing and Treating Offenders with Autism Spectrum Disorder
}

\begin{abstract}
Purpose: Social deficits are central within conceptualisations of autism spectrum disorder (ASD), and seperately linked to offending behaviour. Social problem solving interventions are often used with offenders, but little research has examined the social information processing (SIP) skills of individuals with ASD and a history of criminal offending behaviours.
\end{abstract}

Design/methodology/approach: This conceptual paper will introduce the SIP model, review SIP research as applied to those with ASD and in forensic populations, and further consider the relevance to the assessment and treatment of offenders with ASD.

Findings: Difficulties in all areas of the SIP model are noted in ASD and research suggests these difficulties may be directly linked to behaviour.

Practical implications: It is possible that identifying SIP abilities and deficits could improve the effectiveness of rehabilitation programmes for this group.

Originality/value: This paper reviews the utility of social information models in the offending behaviour of people with ASD. 


\section{The Clinical Utility of Social Information Processing Theory in the Assessment and Treatment of Offenders with Autism Spectrum Disorder}

\section{Introduction}

People with autism spectrum disorder (ASD) who engage in offending behaviour are a small but overrepresented group within the criminal justice system. Although a topic of interest in academic literature, there has been little theoretically driven research. WoodburySmith et al. $(2005 ; 2006 ; 2010)$ highlighted that when considering vulnerability to offending in ASD, risk factors identified in the general criminological literature are relevant, e.g. low IQ, poor educational achievement, and hyperactivity-impulsivity-inattention; as well as ASD specific risk factors, such as poor social understanding, circumscribed interests, difficulties in adjusting to the diagnosis and social exclusion. Social problem solving interventions are considered effective for reducing offending behaviours (e.g. McMurran et al., 1999), and while social deficits are part of the conceptualisation of ASD, and independently linked to offending behaviour, social information processing (SIP) models have not been applied to those with both ASD and a history of criminal offending behaviours. This conceptual paper aims to introduce the SIP model, review SIP research involving both those with ASD, and those with offending behaviours. Furthermore, the utility of SIP models in explaining and treating some of the specific difficulties faced by those with ASD who have a history of criminal offending behaviours will be examined.

\section{What is Social Information Processing and how is it affected in Autism Spectrum Disorder?}

Social information processing (SIP) models aim to increase understanding of antisocial behaviour (van Nieuwenhuijzen et al., 2004; Stickle, Kirkpatrick \& Brush, 2009) and have been described as one of the most fruitful areas of study for understanding the processes implicated in persistent aggression (Bowen, Roberts, Kocian, \& Bartula, 2014; Stickle, Kirkpatrick \& Brush, 2009). The most well-known SIP model is that of Crick and Dodge (1994; 1996; Dodge, 1986; Dodge \& Price, 1994). According to their model, several cognitive steps, or mental processes are used by individuals to create a behavioural response during social interactions. Individuals encode incoming information, interpret this information within the particular social context, set goals, search for possible responses, evaluate response options, and then select a response for enactment (van Nieuwenhuijzen et al., 2004). Since its development, a number of additions have been made to Crick and Dodge's model. For example, Lemerise and Arsenio (2000) incorporated the role emotions play in decision making, along with moral reasoning.

It has been noted that effectively understanding, preventing, and treating antisocial behaviour has been hindered by a lack of clear, integrated theory and empirical findings (Stickle, Kirkpatrick \& Brush, 2009; Dodge \& Pettit, 2003). Though there is a large body of quality research providing empirical support for individual aspects of antisocial development; this largely lacks integration, resulting in the identification of many loosely connected risk factors and predictors of antisocial behaviour. This affects understanding of how identified genetic and biological predispositions, life experiences, cognitive and emotional processes, and sociocultural contexts work together to produce enacted antisocial behaviour, particularly aggression (Dodge \& Pettit, 2003; Garrigan and Langdon, in press).

Garrigan and Langdon (in press) therefore proposed an integrated framework of moral development that incorporates and combines SIP, moral development and associated theories, 
along with neuropsychological constructs. The model is dynamic, in that it allows for change and progress, either via maturation or therapeutic gains; recursive, i.e. allowing for repetition and recurrence, and context-dependent, thus acknowledging the situational nature of behaviour. The framework is reproduced in Figure 1. The outer circle represents the proximal in vivo processes that occur when an individual has to deal with social situations, and is strongly affected by contextual cues. Some of the constructs that affect each step are listed within the model, while the steps and processes are taken from Crick and Dodge $(1994 ; 1996$; Dodge, 1980, 1986), and are also dynamic and recursive, but mature over time, along with moral development, including maturation of somatic or emotional markers, vital for effective social problem-solving. Individuals with ASD have difficulties at various stages of SIP. In the below sections, the six steps within the Garrigan and Langdon (in press) SIP model will be introduced; and the literature relative to ASD and each step described.

\section{Insert Figure 1: Garrigan and Langdon (in press) Integrated Framework of Moral Development}

\section{Step 1: Encoding of Cues}

Step 1 of the model is the encoding of social cues, and involves social attention, emotion recognition, and situational cues. Situational cues partially determine what is encoded, for example, certain cues may trigger emotions (background feelings) which then determine which cues are encoded, while previous experience may bias encoding. Divided and selective attention is also important to attend to multiple relevant features of a situation.

Encoding, via visual attention, supports the selection of salient stimuli, and the suppression of interfering stimuli, from a cluttered visual world (Desimone \& Duncan 1995). As such, it serves as an information filter, determining what is subsequently processed for perception (Amso et al., 2014) and behavioural action. From the very first days of life, typically-developing infants are more attracted to, or biased towards social-like stimuli than to other stimuli, which leads to a strong preference for social stimuli in attention orienting in adulthood (Chevallier et al., 2013). A major source of social information comes from the processing of faces and interpreting facial expressions. Facial expressions convey important information about the emotional state of others (Darwin, 1872/1965). The ability to decode facial information quickly and successfully remains highly adaptive in the social world (Ashwin, Chapman, Colle, \& Baron-Cohen, 2006). Face based social judgment is an intuitive process that involves both perceptual and conceptual skills (Olson \& Marshuetz, 2005). Indeed, nonverbal information from the face is so important that humans may have developed specialized perceptual mechanisms for processing emotional expressions (Ekman, 2003). Recognising the emotions of others is a key component in the development of a theory of mind (ToM) (Ashwin et al., 2006). Evaluation of faces is therefore an important modality of social judgment (Forgeot d'Arc, 2014) and overall SIP, and difficulties in emotion recognition are likely to have a negative effect upon SIP.

Brezis et al. (2014) described people with ASD as both impaired in orienting towards, perceiving and interpreting social stimuli. A considerable body of research has investigated encoding of faces and interpretation of emotional facial expressions in ASD. Individuals with ASD do not process faces in a typical way (Maras \& Bowler, 2014). Typically developing individuals spend greater time looking at faces than those with ASD (Carter et al., 2012). When viewing photographs depicting social scenes (e.g., a group of friends chatting), children with autism look significantly more at the background than at the face or body of the characters (Riby \& Hancock, 2008). People with autism have been found to fixate less on people, faces, and eyes, than on other regions of interest when freely viewing movie clips (Klin et al. 2002; Nakano et al., 2010). Furthermore, Ben-Shalom (2003) suggested that those 
with ASD have reduced memory for social content. Investigating from an eyewitness recall perspective, research identified that "context reinstatement" (where witnesses are encouraged by the interviewer to mentally reconstruct the external (physical) and internal (subjective) states that they experienced during the witnessed event before freely reporting as many details of the event as possible) was problematic for those with ASD and failed to elicit an increase in reporting of correct details. A number of mechanisms have been proposed to underlie this unusual performance (Carter et al. 2012). Maras and Bowler (2014) questioned whether people with ASD fail to encode and bind an event with its contextual detail in the first place, or have difficulties with retrieval. However, multiple authors suggest that memory for social content in ASD is reduced due to difficulties attending to and processing social stimuli at the encoding stage (Klin et al., 2009; Baron-Cohen et al. 1999; Piggot et al. 2004). Authors have also speculated whether sensory issues, such as heightened sensitivity to noise, touch and light interfere with encoding (Maras \& Bowler, 2014).

Emotion recognition is important during encoding (Lemerise \& Arsenio, 2000) so that others' emotions can be correctly encoded and processed when making a moral judgement. Hoffman (2000) stated that knowledge that facial expressions can reflect or mask feelings is a requirement for mature empathic distress. Difficulties with emotional recognition should therefore have a negative effect upon moral development and SIP. Ashwin et al (2006) highlighted a lack of consensus from the many studies evaluating the perception of basic emotional expressions in people with ASD. The authors note that while some studies have found differences, others have reported none. Among the studies that have found basic emotional recognition deficits, performance is typically impaired in negative emotions, including fear, anger, disgust, and sadness. Furthermore, deficits in more complex emotions, such as surprise, and in recognising higher-order mental states such as flirtatiousness have consistently been found (Ashwin et al., 2006). Ashwin et al (2006) note that as performance is only hindered in recognition of certain emotions, the encoding deficit is unlikely to stem from an attentional issue, a general impairment in face or object processing, or an inability to recognise emotional expressions from the face; rather a specific deficit in recognising basic emotional expressions with negative valence. This has provided support for the amygdala theory of autism (Baron-Cohen et al., 2000), as the amygdala is the limbic structure that plays a central role in responses to affective or emotionally charged stimuli. Studies have demonstrated the role of the amygdala in the recognition of certain emotions from facial expressions such as fear, and in making complex social judgements about faces, such as their perceived trustworthiness (Adolphs, Sears, and Piven, 2001). Maras and Bowler (2014) note the amygdala's role in memory consolidation, and in typical individuals, emotionally arousing events are better remembered than neutral, non-arousing events.

The research suggests that people with ASD have different encoding styles, for example, paying attention to static, environmental cues rather than social cues, from faces. Furthermore, accurate encoding is the foundation of the SIP model, and therefore any difficulties at this stage are likely to have ripple effects throughout the SIP process.

\section{Step 2: Interpretation of Cues}

Once a cue has been encoded, it has to be interpreted. Interpreting cues relies on theory of mind (ToM) or mentalisation ability, as an individual must be able to take another's perspective to infer their beliefs and intentions. People with ASD have impaired understanding of mental states and succeed on false belief tasks later than typically developing children, if at all (Baron-Cohen et al., 2000). Intent is a central and omnipresent determinant of moral judgements (Cushman, 2008). Blackshaw et al. (2001) provided an example of the contribution of ToM deficits to the tendency to produce external personal attributions (other person blaming). A negative social interaction (e.g. a friend ignores you) 
can be explained in two ways; one is circumstantial (e.g. they did not see you), involving external situational attributions (blaming the situation), and the other is the friend's personality (e.g. they are rude), which involves making external personal attributions (blaming someone else). The former requires the ability to appreciate the world from another's perspective and therefore adequate ToM. Emotional processes can also influence interpretations at step 2. Other implicated processes when interpretating cues are the evaluation of past performance, self-evaluations and other evaluations (Crick \& Dodge, 1994). Such evaluations require working memory capacity, as individuals need to hold pieces of information in memory to interpret them.

Little research has investigated the way people with ASD attribute intent within social interactions. People with ASD are known to have deficits in theory of mind, or perspective taking, which in turn compromises the extent to which an individual can interpret certain cues, limiting the amount of information considered when making a moral judgment, thus impacting on the ability to attribute intent (Blackshaw et al., 2001). Blackshaw et al. (2001) noted that the making of situational external attributions is inherently complex. The authors also noted that difficulties in interpreting subtle social cues due to theory of mind deficits, are highly likely to influence the way people diagnosed with Asperger syndrome explain social situations. Persons with autism have been shown to have difficulty understanding and interpreting others' intent (D'Entremont \& Yazbek, 2007). Roge and Mullet (2011) predicted that 25 people with Asperger syndrome would show differences from 18 people without Asperger syndrome in scores on a measure of casual attribution, specifically, a bias towards personal (other blaming) as opposed to situational attributions, with regards to negative events. However in this study, no significant differences were found between the two groups, with both groups equally likely to use both personal and situational external attributions. However, although participants with autism were able to use intent, they did so less than their age matched controls when making judgements about blame and forgiveness.

Due to the sociocommunication deficits intrinsic to the ASD diagnosis, this group also have problems in interpreting social cues from speech and conversations, e.g. states such as irony, deception and humor (Persicke, Tarbox, Ranick, St. Clair, 2013). People with autism have trouble understanding nonliteral speech, sarcasm, jokes and metaphorical expression (Jolliffe, \& Baron-Cohen, 1999).

Due to well documented difficulties in theory of mind and sococommunication deficits in ASD, it is likely this step of SIP is affected, thus affecting further SIP steps, and overall behavioural enactment in social situations.

\section{Step 3: Clarification of Goals}

Step 3, the clarification or selection of a goal, relates to an individual's desired outcome in a given social interaction. Crick and Dodge (1994) proposed that individuals bring goal orientations or tendencies to a social situation but also revise these and construct new goals in response to the immediate stimuli; thus situational factors are important. Individuals must be able to think of a goal which they may not have previously experienced, which draws on abstract thinking. Arousal regulation is involved, and refers to an individual's ability to regulate the arousal elicited by the current situation, which may in turn be influenced by temperament and personality factors. Empathic arousal is also important during step 3, as it can be a motivator of moral behaviour (Eisenberg et al., 1995; 2006; 2010; Hoffman, 2000) and will determine goals. Individuals with greater empathic arousal should set more pro-social goals within problematic social situations, and empathy deficits, both cognitive (i.e. ToM) and affective, should have implications for moral development. The difficulties with abstract thinking and imagination in ASD are well documented (Wing \& Gould, 1979). Authors report that lower functioning children with ASD have difficulty with 
sorting tasks that involve abstract categories (Shulman et al. 1995; Ropar and Peebles 2007), though older higher functioning individuals do not appear to have these difficulties (Minshew et al. 2002).

Emotions play a critical role in regulating important processes including memory, perception, attention, and physical response (Geller, 2005). Emotional regulation includes the processes whereby we influence which emotions we have, when we have them, and how we experience and express them and can include decreasing, maintaining, increasing, or substituting an emotion and may occur before an emotional response is activated or during the experience (Geller, 2005). Emotional regulation in ASD is often atypical, with many having an inability to recognise emotions in themselves or in others, being unable to differentiate among emotions, or susceptible to highly variable or overly sensitive arousal states (Geller, 2005). Geller (2005) notes that individuals on the spectrum have additional challenges to the development of a smoothly functioning regulating system. These include neurological differences, fewer opportunities to engage in social "give and take" during critical times of brain growth, sensory and processing differences, and negative experiences from continual teasing or rejection. Others live in a state of constant anxiety fueled by fear, or ruminate, which prolongs rather than regulates negative feeling states. Jahromi et al. (2012) suggested those with ASD use adaptive emotion regulation strategies, such as goal-directed behaviors or social support seeking, less effectively compared with a comparison group. Samson, Huber, and Gross (2012) found that adults with ASD use cognitive reappraisal (a successful, antecedent-focused regulation strategy) less frequently than typically developing counterparts, while using more expressive suppression, which is considered maladaptive in the long term if it is the only available regulatory strategy. Geller (2005) notes that suppression helps some individuals with ASD appear more socially acceptable, but the internal effort required has the negative consequences of distracting from social interplay, increasing isolation, escalating physiological stress, and hindering the growth of relationships because the underlying negative emotions continue and grow.

Also important at step 3, empathy has been the subject of extensive research in ASD. Two processes that contribute to empathy are i) being aware of, and resonating with, the feelings of another individual such that awareness of their emotion drives the same state in oneself (affective resonance) and ii) identifying and understanding what another individual is thinking/feeling without a necessary affective response (cognitive perspective-taking) (Lockwood et al., 2013). The difficulties with cognitive perspective-taking in ASD are well established, while findings from studies assessing affective resonance processes in ASD are less consistent (Lockwood et al., 2013). Capps et al. (1993) reported that affective resonance in ASD is enhanced compared to the general population. Blair $(1996,1999)$ suggests that physiological responsivity to the distress of others is unimpaired in autism. Blair (1996) concluded that high functioning children show some sensitivity to the distress of others, and that mentalising / theory of mind ability is not a prerequisite for sensitivity to this distress. However, Blair notes that although affective resonance appears intact in autism, this is not enough to produce empathic behavioural responses (Frith, 1989; Kanner, 1943; Sigman et al., 1992). Fan et al., (2013) found typical sensori-motor resonance (a neural representation of anothers pain) when viewing others in pain, while Minio-Paluello et al. (2009) later reported an absence of sensori-motor resonance. Affective and cognitive processing profiles have been examined in studies related to psychopathy and ASD (Jones et al., 2012; Schwenck et al., 2013; Lockwood et al., 2013). Those with conduct disorder and psychopathic traits showed less affective resonance with others' emotions but did not have problems with cognitive perspective-taking; while, children with ASD showed reduced cognitive perspective-taking but did not have problems with affective resonance. Lockwood et al. (2013) cautioned that in everyday life, empathic responses to others occur in the context of reciprocal social 
interactions, while the tasks employed in such studies did not replicate these scenarios. However, it is not unreasonable to suggest that intact affective resonance is likely to inhibit or reduce the probability of criminal offending behaviour.

A number of the implicated processes involved in this step are affected in ASD, such as abstract thinking, emotional regulation, empathic responsiveness, and inhibition. It is therefore likely that goal clarification is atypical in.

\section{Step 4: Response Access or Construction}

Step 4 is response access or construction, where an individual accesses from memory possible responses to the situation or constructs new behaviours if the situation is novel. Abstract thought is important for this step as individuals may need to construct a response with which they have no prior experience, or imagine the ideal response. Difficulties with abstract thinking will affect moral development due to the impact upon goal orientations at step 3, and response construction at step 4. The somatic marker hypothesis (SMH) (Damasio, 1994) is relevant as it may automatically lead to the rejection of some outcomes. The SMH proposes that 'somatic marker' biasing signals from the body are represented and regulated in the emotion circuitry of the brain, to help regulate decision-making in situations of complexity and uncertainty. Situational factors may influence, and bias, the responses that are generated at step 4 . The responses accessed or constructed at step 4 are influenced by other steps of processing (e.g. the goal(s) set) and can also be influenced by information stored in the database and emotion processes occurring (e.g. certain moods may bias responses that are constructed). The responses which were not automatically rejected at step 4, are then subject to deliberation at step 5.

This stage also requires working memory, so individuals can access social strategies that have been successful in the past, and abstract thought, if responding to a situation in which they have no prior experience. Individuals with ASD have diminished episodic memory (Lind \& Bowler, 2009). Episodic memory is a primary evolutionary function, which allows for the mental simulation of future events and for individuals to 'test' alternative plans of action without the potential risks associated with actually carrying out those (potentially flawed) plans (Currie, 1995; Schacter \& Addis, 2007; Suddendorf \& Corballis, 1997, 2007). Further, as an individual can consider multiple possible courses of action, episodic future thinking is thought to facilitate behavioural flexibility and self-control (Suddendorf \& Corballis, 2007), as individuals forego immediate gratification in order to achieve long-term gains. Thus, simulation of future events may considerably improve the chances of forming optimal plans of action to guide adaptive future behaviour (Lind \& Bowler, 2009). Channon et al. (2001) examined real-life-type problem-solving among a group of adolescents with Asperger syndrome, compared with a matched typically developing group, using problems based on situations that most people might encounter either directly or indirectly. Those with Asperger syndrome were impaired in several aspects of problem-solving, including recounting the pertinent facts, generating possible high-quality problem solutions, and selecting optimal and preferred solutions. Their solutions differed from the typically developing group in social appropriateness.

\section{Step 5: Moral Judgement}

Moral judgement is step 5 of Garrigan and Langdon's model. A moral judgment is a response decision, about a situation in the moral domain, while moral reasoning is actual processing, using emotional and cognitive processing. Moral judgement has been the subject of a growing body of research in ASD over the past ten years. Differences in moral judgement abilities in ASD are likely, as many implicated skills and processes, such as empathy, decision making skills, the inhibition of inappropriate responses, working memory 
and self-efficacy evaluations may be affected. Moral schema, perspective taking, or theory of mind are also important for moral reasoning and judgement, as taking into account how others may respond can influence how an outcome is evaluated. Research has shown people with ASD who do not have intellectual disabilties experience greater difficulty with decisionmaking when compared with matched controls (Goldstein et al. 2001). Luke et al. (2012) found that people with ASD found decision-making exhausting, and tended to avoid making decisions because they disliked doing so. De Martino et al. (2008) examined decision-making under conditions of uncertainty in ASD and found reduced emotional responses as measured by skin conductance. The authors interpreted the findings as reduced integration of emotion in decision-making in those with ASD, alongside a greater reliance on a rational and logical decision making style. This is consistent with the prominent Empathising-Systemising (E-S) theory (Baron-Cohen 2002, 2003, 2009). According to E-S theory, ASD is characterised by a strength in systemising, which is defined as the drive to analyse or build systems. Systemising represents non-social processing and allows one to predict the behaviour of a system and to control it (Baron-Cohen, 2002).

Christ et al. (2007) suggested that some, but not all, inhibitory processes are affected in ASD, as deficits are shown only on certain tests, with intact inhibition on both the computerised Stroop and a go/no-go task but impairment on a Flanker task. The Flanker and Stroop require inhibitory control at the level of response selection (e.g. MacLeod, 1991). Christ et al. (2007) hypothesised that these difficulties may be due to problems with sustained attention, but note that this pattern of spared and impaired inihibition may be due to inhibition being a complex cognitive process with different fronto-striatal circuits involved, some of which may be more affected in ASD. Further to this, Raymaekers et al. (2004) found that adults with ASD performed poorly on a go/no-go task when stimulus presentation was fast but were able to complete the task when stimulus presentation was slow. The authors interpreted this result as an inability of adults with ASD to modulate arousal rather than a deficit in inhibition. Johnston et al (2011) examined adults with ASD on a variety of inhibition measures, finding that there was a pattern of generally intact response inhibition in adults with ASD, although accuracy was at the expense of speed. However, it is unclear how well these tasks relate to real life inhibition processes.

The literature on moral judgement in ASD was recently reviewed by Patil, Melsbach, Hennig-Fast and Silani (2016). Studies utilised a variety of moral cognition tasks to explore if the capacity to judge third-party harmful behaviours is intact in ASD. In one of the earliest studies, Blair (1996) found that children with autism could distinguish between conventional and moral transgressions, even if they failed false belief theory of mind / mentalising tests. The moral and conventional distinction is the perception of whether the act results in a victim (Smetana, 1981; 1995). The distinction between intentional moral transgressions (that involve a suffering victim whose personal rights are violated; e.g. hitting others) and conventional transgressions (characterized by infraction of normative prohibitions but with no consequence for others' welfare; e.g. talking out of turn) is intact in children and adults with ASD. Li et al (2014) noted that children with high functioning autism (HFA) seemed to have little difficulty in evaluating certain acts (such as hitting and sharing) in terms of their morality. On the contrary, HFA children judged harming others as significantly worse than controls. This indicates that HFA children might have more rigid criteria for what constitutes morally "naughty" actions, possibly due to being more rule-oriented.

Although there are no apparent impairments in evaluating intentional third-party harm-doings, deficits have been observed on more complex intent-based moral judgment tasks that require integration of information about mental states with information about outcomes of these acts. In particular, accidental harms have been judged more harshly than controls, arguably due to an inability to form a robust representation of agent's benign 
intentions due to ToM deficits that can be weighted up against a strong negative emotional response stemming from the victim suffering. Patil et al (2016) note that this work is consistent with the profile of ASD featuring preserved psychophysiological/emotional response to others' affective states (affective empathy) but reduced cognitive understanding about others' internal states (ToM) (e.g. Lockwood et al., 2013). This work also demonstrates how ToM deficits modulate moral judgments about third-party moral violations, but only when these processes operate in tandem with other processes (e.g., harm assessment) that provide conflicting contextual information that needs to be integrated for a final moral judgment. In contrast, Leslie, Mallon, \& Dicorcia (2007) undertook a "cry baby" task, in which the distress of the victim was unreasonable or unjustified, in order to examine whether the distress exhibited by participants with autism in moral / conventional distinction tasks are automatic sympathy reactions to the distress of victims. Although both the moral and the cry baby stories applied featured a character who starts to cry following the actions of another person, only in the moral stories was the action deemed culpable, by both the children with autism and the typically developing children, which suggests that the reaction to distress cues in moral transgressions is not simply of the "knee jerk" type but involves moral reasoning.

The role of empathy in moral condemnation of harmful behaviour was examined by Patil et al (2016) whilst taking into account the recent developments of the alexithymia hypothesis, which theorises that only the deficits observed in the sociocognitive domain are unique to the autism phenotype, while the socioaffective deficits are due to the co-occurring alexithymic phenotype and not a feature of autism per se. Alexithymia is the sub-clinical inability to identify and describe emotions in the self. The rate of clinical levels of alexithymia in general populations is at $10 \%$, and $40-65 \%$ in adults and children with ASD. Therefore, it is important to account for its effects in emotional processing deficits observed in ASD, especially because trait alexithymia itself has been associated with impaired emotional processing (e.g., empathy, emotion regulation, emotional interoception). Thus, it is likely that the emotional processing deficits in ASD are due to the presence of elevated levels of alexithymia. Indeed, after accounting for alexithymia, autism is no longer associated with aberrant neural activation while empathising with others' pain, self-reported deficits on dispositional empathy, or deficits in interocepting on one's own emotional states. Thus, any investigation gauging effects of aberrant emotional skills on moral cognition in ASD should also account for the presence of alexithymia. Brewer et al (2015) explored the role of alexithymia in moral judgments in ASD, revealing that moral judgments were predicted by alexithymia in healthy controls but not in individuals with ASD. This suggests that decisionmaking in ASD was less subject to emotional biases as their moral judgments are not based on emotional information. Further to this, Patil et al. (2016) investigated the role of emotional processing deficits and alexithymia in moral cognition. Those with ASD exhibited a normal pattern of moral judgments, and this stemmed from mutually conflicting biases associated with autistic and alexithymic traits. ASD traits were associated with reduced utilitarian bias due to elevated personal distress of demanding social situations, while alexithymic traits were associated with increased utilitarian bias on account of reduced empathic concern for the victim. Additionally, those with ASD relied on their non-verbal reasoning skills to rigidly abide by harm-norms. Thus, utilitarian moral judgments in autism were spared due to opposite influences of autistic and alexithymic traits and compensatory intellectual strategies.

It also appears that ability to demonstrate moral reasoning in ASD is affected by verbal ability. Grant, Boucher, Riggs and Grayson (2005) assessed the ability of children with autism to make moral judgements. Participants were presented with pairs of vignettes in which actions were either deliberate or accidental and which caused injury to a person or damage to property, and asked to judge which protagonist was the naughtier and to verbally justify this judgement. Results showed that the children with autism were as likely as controls 
to judge culpability on the basis of motive, and to judge injury to persons as more culpable than damage to property. However, the verbal justifications given for their judgments were of poor quality and reiterated the story. Takdea, Kasai, and Kato (2007) investigated moral reasoning level in a Japanese population, finding that the children with ASD sampled were slightly less likely to have reached a morality level of 4 (the move beyond unquestioning support, and subsequent flexible application of the rules) and scored significantly lower on the Human External Action and its internal Reasoning Type (HEART), a standardized test for evaluating moral judgment. However, one of the subscales on this measure relates to empathy, on which those with ASD scored significantly lower, and it is unclear how much this affected the total score overall. The authors concluded that these results did not necessarily imply that children with ASD act less morally than children with typical development. Furthermore, there were significant positive correlations between moral reasoning and verbal ability in the ASD group, while no such correlation emerged in the matched typically developing children. Thus, a simpler methodology is required, which would demand a lower level of language abilities and have less of a cognitive load, while still being a valid and reliable assessment of moral reasoning in ASD (Shulman et al., 2012).

Carter et al. (2012) compared children with autism (ASD) and children with typical development (TD) on the neurofunctional basis of social judgment in a fMRI study. Participants indicated in which of two pictures a boy was being bad (Social condition) or which of two pictures was outdoors (Physical condition). In the within-group Social-Physical comparison, TD children used components of mentalizing and language networks; bilateral inferior frontal gyrus (IFG), bilateral medial prefrontal cortex (mPFC), and bilateral posterior superior temporal sulcus (pSTS)], whereas ASD children used a network that was primarily right IFG and bilateral pSTS, suggesting reduced use of social and language networks during this social judgment task. A direct group comparison on the Social-Physical contrast showed that the TD group had greater $\mathrm{mPFC}$, bilateral IFG, and left superior temporal pole activity than the ASD group. No regions were more active in the ASD group than in the group with TD in this comparison. Both groups successfully performed the task, which required minimal language. The groups also performed similarly on eyetracking measures, indicating that the activation results probably reflect the use of a more basic strategy by the autism group rather than performance disparities. Even though language was unnecessary, the children with TD recruited language areas during the social task, suggesting automatic encoding of their knowledge into language; however, this was not the case for the children with autism. These findings support behavioural research indicating that, whereas children with autism may recognize socially inappropriate behavior, they have difficulty using spoken language to explain why it is inappropriate. The fMRI results indicate that ASD children may not automatically use language to encode their social understanding, making expression and generalization of this knowledge more difficult.

Moral judgement and reasoning is a developing body of research in ASD, and studies suggest a number of differences in these areas, as compared to control groups without ASD, due to difficulties in many of the processes implicated, and in intergrating these processes. As one of the latter stages of the model, where the morality of potential responses to social situations are imagined, it is critical to behavioural enactment, the end point of the model.

\section{Step 6: Behavioural Enactment}

Behavioural enactment is an under researched area, and few have examined the link between SIP domains and behaviour in ASD. Li, Zhu \& Gummerum (2014) investigated moral judgment in children with high-functioning autism and their subsequent cooperation in a prisoner's dilemma game with partners of different moralities. Children were first asked to 
judge story protagonists' morality. After making this moral judgment correctly, they were asked to play with the morally nice and the morally naughty child in a repeated prisoner's dilemma game. Although both groups of children made correct moral judgments, the children with autism did not differentiate their level cooperation depending on the morality of the interaction partner, while typically developing children showed higher cooperation when interacting with the morally nice than the morally naughty child. Futhermore, there is evidence that many individuals with ASD are impaired in self-regulation of social-emotional behaviour (Bachevalier \& Loveland, 2006), or lacking empathic behavioral responses (e.g., Frith, 1989; Kanner, 1943; Sigman et al., 1992).

\section{The Role of SIP Deficits in Offending Behaviour}

SIP difficulties are well documented in populations with offending behaviour. Indeed, the initial developments of the SIP model focused on aggressive children (Crick \& Dodge, 1994; 1996; Dodge, 1986; Dodge \& Price, 1994). Adult offenders have documented difficulties with the encoding and interpretation of social cues (e.g. Hoaken, Allaby, \& Earle, 2007; Schönenberg \&Jusyte, 2014; Gillespie et al., 2015) goal clarification and response construction (Losel \& Beelman, 2008), moral judgement (Palmer, 2003) and intrinsically, the behavioural enactment stages of the Garrigan and Langdon model (in press). Similar findings have been reported in populations of people with intellectual disabilities and difficulties with aggression (Pert, Jahoda, \& Squire, 1999; Jahoda, Pert, \& Trower, 2006; Pert \& Jahoda, 2008; Larkin, Jahoda \& MacMahon, 2013) or offending behaviour (Langdon, Murphy, Clare, Steverson, \& Palmer, 2011). Bowen, Roberts, Kocian, and Bartula (2014) analysed 466 reports of violent and avoided violence situations described by 236 newly incarcerated offenders in order to assess their decision making in these situations. The findings indicated that several situational, social information processing, and emotion variables, such as intent interpretation, goal, and response generation, were significant predictors of the escalation of violence.

Furthermore, social problem solving interventions have been of demonstrated utility in a developing body of research in forensic populations. In a large meta-analysis of studies of the effects of cognitive behaviour therapy on offenders, Landenberger and Lipsy (2005) reported that the programmes most associated with recidivism included interpersonal problem-solving and anger control. McMurran, Egan, Richardson and Ahmadi (1999) measured the social problem solving abilities of nine patients from a secure psychiatric unit using the Social Problem-Solving Inventory - Revised (SPSI-R), pre and post a problemsolving intervention. The patients who participated showed improvements on the overall SPSI-R score and two subscales - reduced negative problem orientation (NPO) and reduced impulsivity/carelessness (ICS). It was therefore concluded that social problem-solving skills training may be of value with mentally disordered offenders.

McMurran, Egan and Duggan (2007) reported the introduction and outcomes of the 'Stop and Think' social problem-solving intervention (Nezu et al., 2007) in a medium secure service for people with personality disorder. The authors reported that significant improvements were made on overall problem solving, and specific subscales of the SPSI-R (rational problem solving, impulsive / careless style, and avoidant style). Furthermore, these improvements occurred rapidly, in the early stages of treatment and were maintained throughout the follow-up to 21 months. Long, Fulton, O Dolley and Hollin (2011) examined the effectiveness of the social problem-solving group intervention with women detained within a forensic mental health service, reporting significant improvements in mood, self efficacy, and overall social problem solving skills, and reduced depression and relationship 
difficulties. Lindsay et al (2011) described the development and outcomes of a social problem solving programme (SPORT) among 10 offenders with intellectual disability, reporting that the group became less impulsive and more positive in their style and orientation towards social problem solving.

The EQUIP programme has also shown utility in reducing recidivism and improving social skills amongst young offenders (Garrigan and Langdon, in press). The EQUIP programme is theoretically robust, and multicomponent in nature, including anger management, cognitive restructuring, problem-solving, and interventions that target moral development, while improving both social skills and problem-solving ability, all of which link to criminal offending behaviour (Garrigan and Langdon, in press). The EQUIP programme comprises two types of treatment sessions: a) Mutual Help Meetings, and b) Equipment Meetings. Mutual Help Meetings provide a forum for participants to discuss their difficulties within a framework that allows for an appropriate resolution, and aims to teach problem-solving. Equipment Meetings are "active treatment" meetings comprising three different types of sessions: a) anger management and thinking error correction, b) social skills training, and c) social decision-making training. Social decision-making aims to enhance moral development through a process of guided discussion and debate about problem situations.

Conversely, much of the research on the SIP model in offenders has focused on interpersonal aggression. However, Calvete and Orue (2011) report that SIP is not equally relevant for all types of aggression. Specifically, SIP seems to be particularly involved in reactive aggressive behaviours, which represent a reaction to a perceived threat and are characterized by intense anger. SIP skills seem less relevant role in proactive aggressive behaviours, which consist of deliberate actions aimed at achieving a desired goal, which is a limitation of the SIP model.

\section{Could SIP Models have Utility in the Assessment and Treatment of Offenders with Autism Spectrum Disorder?}

ASD appears to be overrepresented in forensic settings (e.g. secure hospitals and prisons), with reported rates between 1.5 and 30\% (Scragg \& Shah 1994; Alexander et al. 2011). However, studies are limited by methodological issues including single service samples, highly selected populations and a lack of cohesiveness in the definition and assessment of ASD (Gomez de la Cuesta, 2010). Regardless of exact prevalence rates, there are significant numbers of people with ASD within criminal justice settings.

Research on the outcomes of people with ASD during and following admission to inpatient forensic services, or prison is scarce, and with mixed findings. One study suggested that patients with ASD had similar lengths of stay, and equal likelihood of discharge to settings of lower levels of security to patients without ASD in a forensic intellectual disability service (Esan et al., 2015), though those with ASD were involved in significantly more incidents of physical intervention and received pro re nata (as required) psychotropic medication than patients without ASD (Esan et al., 2015), possibly indicating higher rates of behavioural and mental health disturbance. Murphy (2010) notes that those with ASD can be difficult to engage therapeutically due to difficulties central to the diagnosis; empathy deficits, cognitive rigidity and problems with central cohesion (a tendency to become fixed with specific details rather than an awareness/appreciation of the wider context), a lack of appreciation of the emotional and social consequences of their actions, egocentric view of the world, and dysfunctional coping strategies adopted by individuals to deal with interpersonal conflict. Due to this, patients with ASD patients represent a challenging group of individuals 
for forensic services, and while there are a limited number of specialist ASD forensic units suited to individuals with an ASD, very often such individuals are placed among 'neurotypical' offenders and expected to fit in with conventional therapeutic programmes. One case study also demonstrates that those with ASD can be better defined by services' exclusion criteria, rather than inclusion criteria (Baliousis, Voll, Banerjee \& Duggan, 2013), and as a result, can fall between the borderlines of general forensic, and specialist intellectual disability services.

A new National Service Model for people with neurodevelopmental disabilities has recently been published (Local Government Association, Association of Directors of Adult Social Services, \& NHS England, 2015) which focuses on ensuring that individuals with behaviour described as challenging are afforded the highest quality care within their communities, rather than having to be admitted to hospital. In order to prevent such admissions, and ensure patients can be discharged safely, a robust understanding of their psychological needs is required, in order to effectively target rehabilitative treatments. However, at present, research focusing on this group has remained at the case study, or case control study level, with minimal cognitive theoretically driven research (excepting Woodbury-Smith et al., 2005; 2006; 2010).

A developing body of research has examined various aspects of social information processing in ASD, suggesting that people with autism are poorer at reasoning about what others think, know or believe, recognizing emotional expressions and gestures, and making social attributions and judgments (Bachevalier \& Loveland, 2006). Despite this, little research has examined the link between social information processing and behaviour which reaches a criminal threshold in ASD, excepting Woodbury-Smith et al., (2005). WoodburySmith et al. (2005) investigated whether the cognitive impairments and social understanding of people with ASD; theory of mind, executive function, and emotion recognition, are associated with vulnerability to offending. ASD offenders showed specific impairments in recognition of emotional expressions of fear, but no difference in theory of mind, executive function, and recognition of facial expressions of sadness, as compared with those with ASD that were non-offending. Furthermore, SIP are evident in some of the case studies of offending behaviour in ASD. For example, Murphy (2010) described a case whose inability to apply rules flexibly was a direct precursor to their offending behaviour.

In light of these findings, Langdon, Murphy, Clare, Palmer and Rees (2013) piloted the Equipping Youth to Help One Another Programme within a NHS medium-secure inpatient service, with four men with Asperger Syndrome, and three men with intellectual disabilities, over four weekly sessions for 12 weeks. The authors reported that there were improvements in moral reasoning, distorted cognitions, and some aspects of problem-solving ability at post-treatment. The authors suggested that the programme is likely to have a positive impact upon the culture of services, via the creation of a positive-peer culture, while the group is not offence specific, like other treatment programmes for offenders with IDs, meaning that offenders are not grouped by offence-type when accessing group-based psychological therapies.

\section{Conclusions}

In an attempt to further understand the offending behaviour of people with autism spectrum disorder (ASD), we have considered the potential utility of social information processing (SIP) models. As noted, this population are overrepresented in forensic settings, and have been described as posing challenges, with high rates of behavioural incidents, and 
lack of fit in conventional therapeutic programmes, arguably due to a lack of theoretically driven research.

Models of social information processing have been described as one of the most fruitful areas of study for understanding the cognitive processes implicated in persistent aggression (Bowen et al., 2014; Stickle et al, 2009; Lindsay et al., 2011). Difficulties in these domains have been consistently linked to behavioural outcomes, and SIP interventions have repeatedly shown effective results across a wide range of offender populations. The studies reviewed have suggested that individuals with ASD have difficulties at various stages of social information processing, and that these difficulties may be directly linked to behaviour.

It is therefore recommended that future research comprehensively examines the performance of offenders with ASD across SIP domains, as well as the link between these deficits and offending behaviour. It is possible that such research could improve the effectiveness of preventative and rehabilitation programmes for this group. Although a number of clinical interventions which are based upon social problem-solving and moral development for offenders with intellectual disabilities are emerging, people with ASD have not been the focus, and this research is in its early stages. There is clearly a need for much larger studies evaluating the utility of treatments incorporating SIP principles, such as EQUIP, however due to the lack of research, smaller scale studies may be helpful at this point. 
Figure 1: Garrigan and Langdon (in press) Integrated Framework of Moral Development

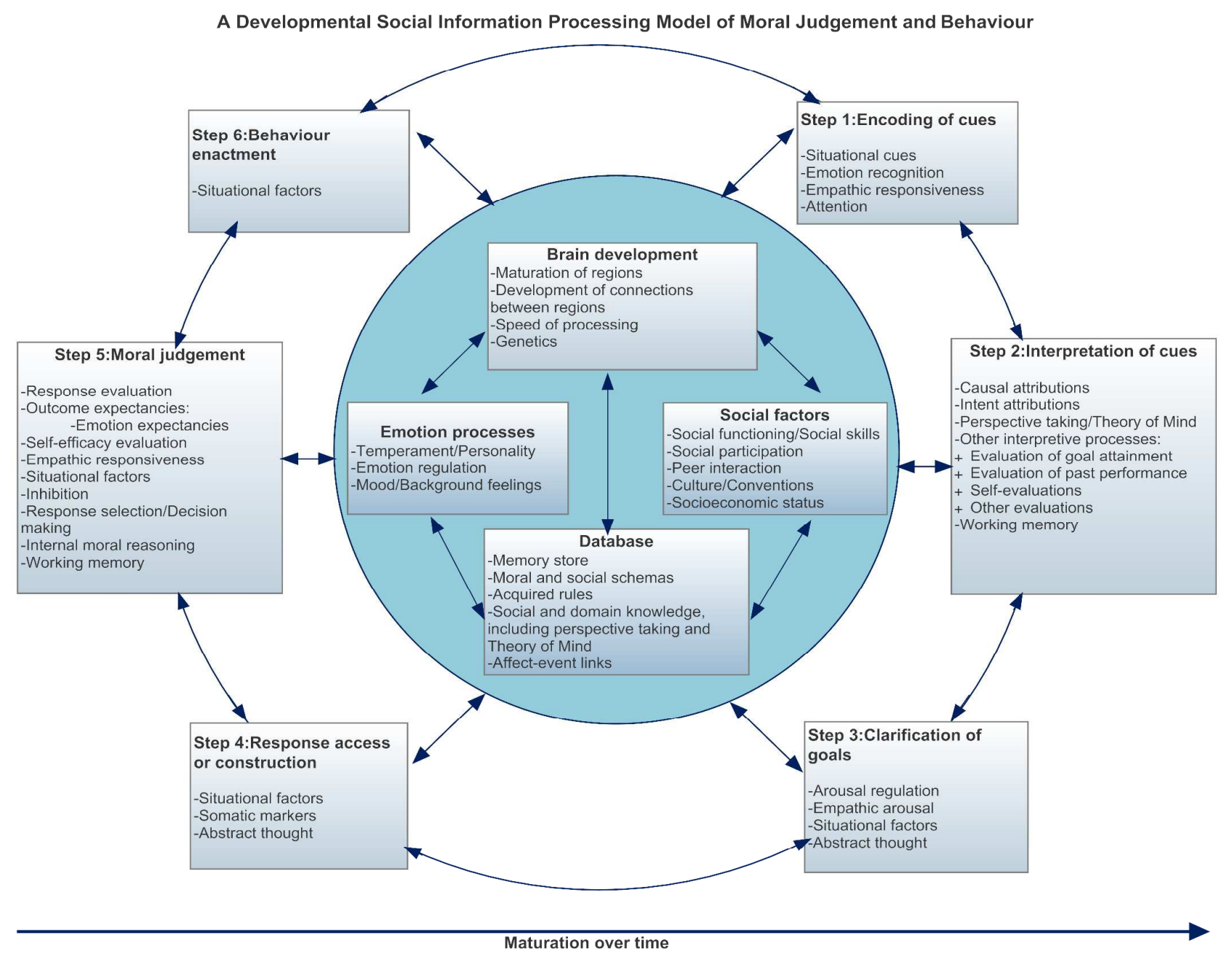




\section{References}

Adolphs, R., Sears, L., \& Piven, J. (2001). Abnormal Processing of Social Information from Faces in Autism. Journal of Cognitive Neuroscience, 12(2), 232-240.

Alexander R. T., Hiremath A., Chester V., Green F. N., Gunaratna I. J. \& Hoare S. (2011) Evaluation of treatment outcomes from a medium secure unit for people with intellectual disability. Advances in Mental Health and Intellectual Disabilities, 5, $22-32$.

Amso, D., Haas, S., Tenenbaum, E., Markant, J., \& Sheinkopf, S. (2014). Bottom-Up Attention Orienting in Young Children with Autism. Journal of Autism and Developmental Disorders, 44, 664-673.

Ashwin, C., Chapman, E., Colle, L. \& Baron-Cohen, S. (2006). Impaired recognition of negative basic emotions in autism: A test of the amygdala theory. Social Neuroscience, 1 (3-4), 349-363.

Baird, A. (2008). Adoescent moral reasoning: The integration of emotion and cognition. In W. Sinnott-Armstrong (Ed.), The Neuroscience of Morality: Emotions, Brain Disorders, and Development (Vol. 3, pp. 323-343). London: The MIT Press.

Baliousis, M., Vollm, B.A., Banerjee, P. \& Duggan, C. (2013). Autistic spectrum disorder, personality disorder and reading disability: a complex case that falls between the cracks? Journal of Forensic Psychiatry \& Psychology,24(2) 286-292.

Baron-Cohen, S., Tager-Flusberg, H. \& Cohen, D. (eds) (2000). Understanding Other Minds: Perspectives From Developmental Cognitive Neuroscience. Oxford: Oxford University Press.

Baron-Cohen, S. (2002). The extreme male brain theory of autism. Trends in Cognitive Sciences, 6, 248-254.

Baron-Cohen, S. (2009). Autism: The Empathizing-Systemizing (E-S) Theory. Annals of the New York Academy of Sciences, 1156, 68-80.

Baron-Cohen, S., O’Riordan, M., Stone, V., Jones, R.K. (1999). Recognition of faux pas by normally developing children and children with Asperger syndrome or highfunctioning autism. Journal of Autism and Developmental Disorders, 29, 407-418.

Baron-Cohen, S. (2003). The essential difference: Men, women and the extreme male brain. London: Penguin books.

Baron-Cohen, S., Ring, H.A., Bullmore, E.T., Wheelwright, S., Ashwin, C., \& Williams, S.C.R. (2000). The amygdala theory of autism. Neuroscience and Biobehavioural Reviews, 24, 355-364. 
Bachevalier, J. \& Loveland, K.A. (2006). The orbitofrontal-amygdala circuit and selfregulation of social-emotional behavior in autism. Neuroscience and Biobehavioral Reviews, 30, 97-117.

Ben-Shalom, D. (2003). Memory in autism: review and synthesis. Cortex, 39(4-5) 1129-38.

Blackshaw, A.J., Kinderman, P., Hare, D.J., \& Hatton, C. (2001). Theory of mind, causal attribution and paranoia in Asperger syndrome. Autism, 5(2) 147-63.

Blair, R.J.R. (1996). Brief Report: Morality in the Autistic Child. Journal of Autism and Developmental Disorders, 26, 571-9.

Blair, R. J.R. (1999). Psychophysiological Responsiveness to the Distress of Others in Children with Autism. Personality and Individual Differences, 26, 477-85.

Bowen, K.L., Morgan, J.E., Moore, S.C., van Goozen, S.H.M. (2014). Young Offenders' Emotion Recognition Dysfunction Across Emotion Intensities: Explaining Variation Using Psychopathic Traits, Conduct Disorder and Offense Severity. Journal of Psychopathology and Behavioral Assessment, 36(1) 60-73.

Brewer, R. et al. (2015) The impact of autism spectrum disorder and alexithymia on judgments of moral acceptability. Journal of Abnormal Psychology, 124, 589-95.

Brezis, R.S., Galili, T., Wong, T., \& Piggot, J.I. (2013). Impaired Social Processing in Autism and its Reflections in Memory: A Deeper View of Encoding and Retrieval Processes. Journal of Autism and Developmental Disorders, 44(5) 1183-1192.

Carter, E.J., Williams, D.L., Minshew, N.J., \& Lehman, J.F. (2012). Is He Being Bad? Social and Language Brain Networks during Social Judgment in Children with Autism. PLoS ONE 7(10) 47241.

Calvete, E., \& Orue, I. (2011). The impact of violence exposure on aggressive behavior through social information processing in adolescents. American Journal of Orthopsychiatry, 81(1) 38-50.

Capps, L., Kasari, C., Yirmiya, N. and Sigman, M. (1993). Parental perception of emotional expressiveness in children with autism. Journal of Consulting and Clinical Psychology, 61(3), 475.

Channon, S., Charman, T., Heap, J., Crawford, S., \& Rios, P. (). Real-Life-Type ProblemSolving in Asperger's Syndrome. Journal of Autism and Developmental Disorders, 31(5) 461-469.

Chevallier, C., Huguet, P., Happé, F., George, N., Conty, L. (2013). Salient Social Cues are Prioritized in Autism Spectrum Disorders Despite Overall Decrease in Social Attention. Journal of Autism and Developmental Disorders, 43, 1642-1651.

Christ, S. E., Holt, D. D., White, D. A., \& Green, L. (2007). Inhibitory control in children with autism spectrum disorders. Journal of Autism and Developmental Disorders, $37,1155-1165$. 
Crick, N. R., \& Dodge, K. A. (1994). A review and reformation of social informationprocessing mechanisms in children's social adjustment. Psychological Bulletin, 115, 74-99.

Crick, N. R., \& Dodge, K. A. (1996). Social information-processing mechanisms in reactive and proactive aggression. Child Development, 67, 993-1002.

Cushman, F. (2008). Crime and punishment: distinguishing the roles of causal and intentional analyses in moral judgment. Cognition, 108, 353-380.

D'Entremont, B. and Yazbek, A. (2007). Imitation of intentional and accidental actions by children with autism. Journal of Autism and Developmental Disorders, 37, 16651678.

Damasio, R. (1994). Descartes' Error: Emotion, Reason, and the Human Brain. New York: Harper Collins.

Darwin, C. (1872/1965). The Expression of the Emotions in Man and Animals. London: John Murray.

De Martino, B., Harrison, N. A., Knafo, S., Bird, G., \& Dolan, R. J. (2008). Explaining enhanced logical consistency during decision making in autism. Journal of Neuroscience, 28, 10746-10750.

Desimone, R., \& Duncan, J. (1995). Neural mechanisms of selective visual attention. Annual Reviews of Neuroscience, 18, 193-222.

Dodge, K.A. \& Pettit, G.S. (2003). A Biopsychosocial Model of the Development of Chronic Conduct Problems in Adolescence. Developmental Psychology, 39(2) 349-371.

Dodge, K.A. (1980). Social cognition and children's aggressive behavior. Child Development, $51,162-170$.

Dodge, K.A. (1986). A social information processing model of social competence in children. In P.M. (Ed.), The Minnesota Symposium on Child Psychology (Vol. 18, pp. 37-51). Hillsdale, NJ: Erlbaum.

Dodge, K.A., \& Price, J.M. (1994). On the relation between social information-processing and socially competent behavior in early school-aged children. Child Development, $65,1385-1397$.

D'Zurilla, T. J., Nezu, A. M., \& Maydeu-Olivares, A. (2004). Social problem-solving: theory and assessment Social Problem Solving: Theory, Research and Training (pp. 11-27). Washington, D.C.: American Psychological Association.

Eisenberg, N., Carlo, G., Murphy, B., \& Court, P. v. (1995). Prosocial Development in Late Adolescence: A Longitudinal Study. Child Development, 66(4), 1179-1197. doi: $10.2307 / 1131806$ 
Eisenberg, N., Eggum, N. D., \& Edwards, A. (2010). Empathy-related responding and moral development. In W. F. Arsenio \& E. A. Lemerise (Eds.), Emotions, aggression and morality in children: bridging development and psychopathology. Washington DC: American Psychological Association.

Eisenberg, N., Spinrad, T., L., \& Sadovsky, A. (2006). Empathy-Related Responding in Children. In M. Killen \& J. G. Smetana (Eds.), Handbook of Moral Development (pp. 517-551). Mahwah, New Jersey London: Lawrence Erlbaum Associates.

Ekman, P. (2003). Emotions revealed. London: Weidenfeld \& Nicolson.

Esan, F., Chester, V., Alexander, R. T., Gunaratna, I. J., \& Hoare, S. (2015). An analysis of the clinical, forensic, and treatment outcome factors of those with Autistic Spectrum Disorders treated in Forensic Intellectual Disability Settings. Journal of Applied Research in Intellectual Disabilities, 28(3) 193-200.

Fan, Y-T., Chen, C., Chen, S-C., Decety, J. \& Cheng, Y. (2014). Empathic arousal and social understanding in individuals with autism: evidence from fMRI and ERP measurements. Social Cognitive and Affective Neuroscience, 9(8):1203-1213.

Forgeot d'Arc, B. et al (2014) Atypical Social Judgment and Sensitivity to Perceptual Cues in Autism Spectrum Disorders. Journal of Autism and Developmental Disorders, 46(5) 1574-1581.

Frith, U. (1989). Autism and "Theory of Mind". In C. Gillberg (Ed.), Diagnosis and Treatment of Autism. (pp. 33-52). New York: Plenum Press.

Gaigg, S.B., Gardiner, J.M., \& Bowler, D.M. (2008). Free recall in autism spectrum disorder: The role of relational and item specific encoding. Neuropsychologia, 46, 983-992.

Garrigan, B. \& Langdon, P.E. (In Press). Social problem solving and moral development. In W.R. Lindsay and J.L. Taylor (Eds). The Wiley Handbook on Offenders with Intellectual and Developmental Disabilities. John Wiley and Sons Ltd.

Gathercole, S.E. (1998). The development of memory. Journal of Child Psychology and Psychiatry, 39(1), 3-27.

Geller, H. (2005). Emotional Regulation and Autism Spectrum Disorders. Available from: http://aspergercenter.com/articles/Emotional-Regulation-and-Autism-Spectrum.pdf. Accessed 31 May 2015.

Gillespie, S.M., Rotshtein, P., Satherley, R-M., Beech, A.R. \& Mitchell, I.J. (2015). Emotional expression recognition and attribution bias among sexual and violent offenders: a signal detection analysis. Frontiers in Psychology, 6, 595.

Goldstein, G., Johnson, C.R., \& Minshew, N.J. (2001). Attentional processes in Autism. Journal of Autism and Developmental Disorders, 31, 433-440. 
Gomez de la Cuesta G. (2010) A selective review of offending behaviour in individuals with autism spectrum disorders. Journal of Learning Disabilities and Offending Behaviour, 1, 47-58.

Grant, C.M., Boucher, J., Riggs, K.J., and Andrew Grayson (2005). Moral understanding in children with autism. Autism, 9(3) 317-331.

Herrick SM, Elliott TR. (2001). Social problem-solving abilities and personality disorder characteristics among dual-diagnosed persons in substance abuse treatment. Journal of Clinical Psychology, 57(1) 75-92.

Hoaken, P.N.S., Allaby, D.B., \& Earle, J. (2007). Executive Cognitive Functioning and the Recognition of Facial Expressions of Emotion in Incarcerated Violent Offenders, Non-Violent Offenders, and Controls. Aggressive Behavior, 33, 1-10.

Jahoda, A., Pert, C., \& Trower, P. (2006). Socioemotional Understanding and Frequent Aggression in People With Mild to Moderate Intellectual Disabilities. American Journal on Mental Retardation, 111(2) 77-89.

Jahromi, L.B., Meek, S.E., \& Ober-Reynolds, S. (2012). Emotion regulation in the context of frustration in children with high functioning autism and their typical peers. Journal of Child Psychology and Psychiatry, 53, 1250-1258.

Johnston, K., Madden, A. K., Bramham J., Russell, A.J. (2001). Response Inhibition in Adults with Autism Spectrum Disorder Compared to Attention Deficit/Hyperactivity Disorder. Journal of Autism and Developmental Disorders, 41(7) 903-12.

Jolliffe, T. \& Baron-Cohen, S. (1999). The Strange Stories Test: A Replication with HighFunctioning Adults with Autism or Asperger Syndrome. Journal of Autism and Developmental Disorders, 29(5) 395-406.

Jones, A. P., Happé, F. G., Gilbert, F., Burnett, S., and Viding, E. (2010). Feeling, caring, knowing: different types of empathy deficit in boys with psychopathic tendencies and autism spectrum disorder. Journal of Child Psychology and Psychiatry, 51(11), 1188-1197.

Kanner, L. (1943) Autistic disturbances of affective contact. Nervous Child, 2, 217-250

Klin, A., Jones, W., Schultz, R., Volkmar, F., \& Cohen, D. (2002). Visual fixation patterns during viewing of naturalistic social situations as predictors of social competence in individuals with autism. Archives of General Psychiatry, 59(9) 809-816.

Klin, A., Lin, D. J., Gorrindo, P., Ramsay, G. \& Jones, W. (2009). Two-year-olds with autism orient to non-social contingencies rather than biological motion. Nature, 459, $257-$ 261.

Klingberg, T., Forssberg, H., \& Westerberg, H. (2002). Increased brain activity in frontal and parietal cortex underlies the development of visuospatial working memory capacity during childhood. Journal of Cognitive Neuroscience, 14(1) 1-10. 
Landenberger NA, Lipsy MW. (2005). The positive effects of cognitive-behavioural programmes for offenders: a meta-analysis of factors associated with effective treatment. Journal of Experimental Criminology, 1, 451-76.

Langdon, P. E., Murphy, G. H., Clare, I. C. H., Steverson, T., \& Palmer, E. J. (2011). Relationships among moral reasoning, empathy and distorted cognitions amongst men with intellectual disabilities and a history of criminal offending. American Journal on Intellectual and Developmental Disabilities, 116, 438-456.

Langdon, P. E., Murphy, G. H., Clare, I. C. H., Palmer, E. J., \& Rees, J. (2013). An evaluation of the EQUIP treatment programme with men who have intellectual or other developmental disabilities. Journal of Applied Research in Intellectual Disabilities, 26(2), 167-180.

Larkin, P., Jahoda, A., \& MacMahon, K. (2013). The Social Information Processing Model as a Framework for Explaining Frequent Aggression in Adults with Mild to Moderate Intellectual Disabilities: A Systematic Review of the Evidence. Journal of Applied Research in Intellectual Disabilities, 26(5) 447-465.

Lemerise, E. A., \& Arsenio, W. F. (2000). An integrated model of emotion processes and cognition in social information processing. Child Development, 71(1) 107-118.

Leslie, A.M., Mallon, M. \& Dicorcia, J.A. (2006). Transgressors, victims, and cry babies: Is basic moral judgment spared in autism? Social Neuroscience, 1(3-4) 270-283.

Li, J. Liqi Zhu, L. \& Gummerum, M. The relationship between moral judgment and cooperation in children with high-functioning autism. Scientific Reports, 4, 431.

Lind, S. E., \& Bowler, D. M. (2009). Episodic memory and episodic future thinking in adults with autism. Journal of Abnormal Psychology, 119(4) 896-905.

Lindsay, W.R., Hamilton, C., Moulton, S., Scott, S., Doyle, M. \& McMurran, M. (2011). Assessment and treatment of social problem solving in offenders with intellectual disability. Psychology, Crime \& Law, 17(2) 181-197.

Local Government Association, Association of Directors of Adult Social Services, NHS England (2015). Supporting people with a learning disability and/or autism who have a mental health condition or display behaviour that challenges: draft service model for commissioners of health and social care services. London: Author.

Lockwood, P.L., Bird, G., Bridge, M., \& Viding, E. (2013). Dissecting empathy: high levels of psychopathic and autistic traits are characterised by difficulties in different social information processing domains. Frontiers in Human Neuroscience, 7, 760.

Long, C.G., Fulton, B., O Dolley B.A. and Hollin, C. R. (2011). Social problem-solving interventions in medium secure settings for women. Medicine, Science and the Law, $51,215-219$. 
Losel, F. \& Beelman, A. (2005). Social Problem Solving Programs for Preventing Antisocial Behaviour in Children and Youth. In: M McMurran \& J McGuire (Eds.) Social Problem-Solving and Offending, pp. 127-144. Chichester, UK: Wiley.

Loveland KA, Pearson DA, Tunali-Kotoski B, Ortegon J, Gibbs MC (2001). Judgments of social appropriateness by children and adolescents with autism. Journal of Autism and Developmental Disorders, 31, 367-376.

Luke, L., Clare, I.C.H., Ring, H., Redley, M. and Watson, P. (2012). Decision making difficulties experienced by adults with autism spectrum conditions. Autism, 16, 612621.

MacLeod CM. (1991). Half a century of research on the Stroop effect: an integrative review. Psycholigcal Bulletin, 109, 163-203.

Maras, K. L., \& Bowler, D. M. (2014). Eyewitness Testimony in Autism Spectrum Disorder: A Review. Journal of Autism and Developmental Disorders, 44, 2682-2697.

McMurran M, Egan V, Duggan C. (2005). 'Stop and Think' social problem-solving therapy with personality disordered offenders. In: McMurran M, McGuire J eds. Social Problem Solving and Offending. Chicester UK: Wiley, 207-20.

McMurran, M., Egan, V., Richardson, C., \& Ahmadi, S. (1999). Social problem solving in mentally disordered offenders: a brief report. Criminal Behaviour and Mental Health, 9(4) 315-322.

Minshew NJ, Meyer J, Goldstein G. (2002). Abstract reasoning in autism: a dissociation between concept formation and concept identification. Neuropsychology, 16(3) 32734.

Minio-Paluello, I., Baron-Cohen, S., Avenanti, A., Walsh, V., \& Aglioti, S.M. (2009). Absence of Embodied Empathy During Pain Observation in Asperger Syndrome. Biological Psychiatry, 65, 55- 62.

Murphy, D. (2010). Extreme violence in a man with an autistic spectrum disorder: assessment and treatment within high-security psychiatric care. The Journal of Forensic Psychiatry \& Psychology, 21(3) 462-477.

Nakano, T., Tanaka, K., Endo, Y., Yamane, Y., Yamamoto, T., Nakano, Y., et al. (2010). Atypical gaze patterns in children and adults with autism spectrum disorders dissociated from developmental changes in gaze behaviour. Biological Sciences, 277(1696), 2935-2943.

Nezu, A.M., D’Zurilla TJ, Zwick ML, Nezu CM. (2007). Problem-solving therapy for adults. In: Chang EC, D’Zurilla TJ, Sanna LJ eds. Social Problem-Solving: Theory, Research and Training. Washington, DC: American Psychological Association, $171-81$.

Olson, I.R., \& Marshuetz, C. (2005). Facial attractiveness is appraised in a glance. Emotion, 5(4) 498-502. 
Palmer, E. (2003). An Overview of the Relationship Between Moral Reasoning and Offending. Australian Psychologist, 38(3) 165-174.

Persick, A., Tarbox, J., Ranick, J., St. Clair, M. (2013). Teaching children with autism to detect and respond to sarcasm . Research in Autism Spectrum Disorders, 7(1), 193198.

Pert, C. \& Jahoda, A. (2008). Social goals and conflict strategies of individuals with mild to moderate intellectual disabilities who present problems of aggression. Journal of Intellectual Disability Research, 52(5) 393-403.

Pert, C., Jahoda, A., \& Squire, J. (1999). Attribution of Intent and Role-Taking: Cognitive Factors as Mediators of Aggression With People Who Have Mental Retardation. American Journal on Mental Retardation, 104(5) 399-409.

Pierce, K., Glad, K.S., \& Schreibman, L. (1997). Social perception in children with autism: An attentional deficit? Journal of Autism and Developmental Disorders, 27: 265282.

Piggot, J., Kwon, H., Mobbs, D., Blasey, C., Lotspeich, L., Menon, V., Bookheimer, S., Reiss A.L. (2004). Emotional attribution in high-functioning individuals with autistic spectrum disorder: a functional imaging study. Journal of American Academy of Child and Adolescent Psychiatry. 43(4) 473-80.

Preston, S.D. (2007). A perception-action model for empathy. Cambridge: Cambridge University Press.

Raymaekers, R., van der Meere, J. \& Roeyers, H. (2004). Event-Rate Manipulation and its Effect on Arousal Modulation and Response Inhibition in Adults With High Functioning Autism. Journal of Clinical and Experimental Neuropsychology, 26(1) 74-82.

Riby, D. M., \& Hancock, P. J. B. (2008). Viewing it differently: Social scene perception in Williams syndrome and autism. Neuropsychologia, 46(11), 2855-2860.

Rogé, B. \& Mullet, E. Blame and forgiveness judgements among children, adolescents and adults with autism. Autism, 15(6) 702-712.

Ropar, D., \& Peebles, D. (2007). Sorting preference in children with autism: the dominance of concrete features. Journal of Autism and Developmental Disorders, 37(2) 270-80.

Samson, A.C., Huber, O., \& Gross, J.J. (2012). Emotional reactivity and regulation in adults with autism spectrum disorders. Emotion, 12, 659-665.

Samson, A.C., Hardan, A.Y., Podell, R.W., Phillips, J.M. \& Gross, J.J. (2014). Emotion Regulation in Children and Adolescents With Autism Spectrum Disorder. Autism Research, 8(1) 9-18. 
Schacter, D.L. \& Addis, D.R. (2007). The cognitive neuroscience of constructive memory: remembering the past and imagining the future. Philosophical transactions of the Royal Society of London, 29, 362(1481) 773-786.

Schönenberg, M., \& Jusyte, A. (2014). Investigation of the hostile attribution bias toward ambiguous facial cues in antisocial violent offenders. Eur Arch Psychiatry Clin Neurosci, 264(1) 61-9.

Schwenck, C., Mergenthaler, J., Keller, K., Zech, J., Salehi, S., Taurines, R., Romanos, M. Schecklmann, M., Schneider., W. Warnke., A. \& Freitag, C. (2012). Empathy in children with autism and conduct disorder: group-specific profiles and developmental aspects. Journal of Child Psychology and Psychiatry, 53(6), 651-659.

Scragg, P. \& Shah, A. (1994). Prevalence of Asperger's syndrome in a secure hospital. The British Journal of Psychiatry, 165, 679-682.

Shulman, C., Yirmiya, N., \& Greenbaum, C.W. (1995). From categorization to classification: A comparison among individuals with autism, mental retardation, and normal development. Journal of Abnormal Psychology, 104, 601-609.

Sigman, M.D., Kasari, C., Jung-Hye Kwon, J-H., \& Yirmiya, N. (1992). Responses to the Negative Emotions of Others by Autistic, Mentally Retarded, and Normal Children. Child Development, 63(4) 796-807.

Smetana, J. (1981). Preschool children's conceptions of moral and social rules. Child Development, 52, 1333-1336.

Smetana, J. G. (1995). Morality in context: Abstractions, ambiguities and applications. In R. Vasta (Ed.), Annals of child development: A research annual, 10, pp. 83-130. London: Jessica Kingsley Publishers.

Solomon, M., Buaminger, N., \& Rogers, S.J. (2011). Abstract Reasoning and Friendship in High Functioning Preadolescents with Autism Spectrum Disorders. Journal of Autism and Developmental Disorders, 41, 32-43.

Stickle, T.R., Kirkpatrick, N.M., \& Brush, L.N. (2009). Callous-Unemotional Traits and Social Information Processing: Multiple Risk-Factor Models for Understanding Aggressive Behavior in Antisocial Youth. Law and Human Behavior, 33, 515-529.

Schwenck C., Mergenthaler J., Keller K., Zech J., Salehi S., Taurines R., et al. (2012). Empathy in children with autism and conduct disorder: group-specific profiles and developmental aspects. Journal of Child Psychology and Psychiatry, 53 651-659.

Suddendorf, T., \& Corballis, M.C. (1997). Mental time travel and the evolution of the human mind. Genetic Social and General Psychology Monographs, 123 (2) 133-67.

Suddendorf, T., Corballis M.C. 2007 The evolution of foresight: what is mental time travel and is it unique to humans? Behavioral and Brain Sciences, 30, 299-313 
Takdea, T., Kasai, K., \& Kato, N. (2007). Moral judgment in high-functioning pervasive developmental disorders. Psychiatry and Clinical Neurosciences, 61, 407-414.

Turiel, E. (1998). The development of morality. In W. Damon \& N. Eisenberg (Eds.), Handbook of Child Psychology: Social, Emotional, and Personality Development (5th ed., Vol. 3, pp. 863-932). New York: Wiley.

van Nieuwenhuijzen, M., Orobio de Castro, B., Wijnroks, L., Vermeer, A., \& Matthys, W. (2004). The relations between intellectual disabilities, social information processing, and behaviour problems. European Journal of Developmental Psychology, 1-3, 215229.

Woodbury-Smith, M. Clare, I., Holland, A.J., Watson, P.C., Bambrick, M., Kearns, A. and Staufenberg, E. (2010). Circumscribed interests and 'offenders' with autism spectrum disorders: a case-control study. The Journal of Forensic Psychiatry \& Psychology, 21(3) 366-377.

Woodbury-Smith, M. R., Clare, I. C. H., Holland, A. J., Kearns, A., Staufenberg, E., \& Watson, P. (2005). A case-control study of offenders with high functioning autistic spectrum disorders. Journal of Forensic Psychiatry \& Psychology, 16(4) 747-763.

Woodbury-Smith, M.R., Clare, I. C. H., Holland, A.J., \& Kearns, A. (2006). High functioning autistic spectrum disorders, offending and other law-breaking: findings from a community sample. The Journal of Forensic Psychiatry \& Psychology, 17(1) 108-120. 